\title{
Desafios da patrimonialização do imaterial no caso da prática performativa do "jongo"
}

\author{
Regina Abreu \\ Universidade Federal do Estado do Rio de Janeiro (UNIRIO)
}

Sabrina Dinola

Doutoranda do Programa de Pós-Graduação em Memória Social na Universidade Federal do Estado do Rio de Janeiro

(UNIRIO)

\begin{abstract}
Resumo: O artigo focaliza os desafios da patrimonialização do imaterial no caso da prática performativa do jongo, refletindo sobre instâncias que as políticas de patrimonialização do imaterial viabilizam ou novos modos de criação de valor (ou de conhecimento vivo). Ressaltamos que o processo de mobilização é tão importante quanto as objetificações cujo registro ou preservação ou propriedade se trata. Assim, grupos os mais diversos, mas notadamente de matrizes étnicas afroindígenas (ressaltamos esse aspecto, pois comunica com as narrativas de miscigenação caras ao modernismo brasileiro) se iconizam mutuamente, e adquirem protagonismo e maestria, não por concessão ou adequação, e sim como desafio de abertura dos quadros estreitos da nacionalidade para horizontes contemporâneos e outros futuros possíveis.
\end{abstract}

Palavras-Chave: Patrimônio imaterial; Performance; Jongo. 


\title{
Challenges of the patrimonialization of the immaterial in the case of the performative practice of the "jongo"
}

\begin{abstract}
The article focuses on the challenges of the patrimonialisation of the intangible in the case of the performative practice of jongo, reflecting on instances that the patrimonialization policies of the intangible make feasible or new ways of creating value (or living knowledge). We emphasize that the process of mobilization is as important as the objectifications whose registration or preservation or ownership is concerned. Thus, groups of the most diverse, but especially Afroindigenous ethnic matrices (we emphasize this aspect, because it communicates with the narratives of miscegenation facing Brazilian modernism) are mutually symbolic and acquire protagonism and mastery, not by concession or adequacy, but as a challenge of opening the narrow nationality frameworks to contemporary horizons and other possible futures.
\end{abstract}

Keywords: Intangible heritage; Performance; Jongo.

\section{Desafíos de la patrimonialización del inmaterial en el caso de la práctica performativa del "jongo"}

Resumen: El artículo enfoca los desafíos de la patrimonialización del inmaterial en el caso de la práctica performativa del jongo, reflexionando sobre instancias que las políticas de patrimonialización del inmaterial viabilizan o nuevos modos de creación de valor (o de conocimiento vivo). Resaltamos que el proceso de movilización es tan importante como las objetivaciones cuyo registro o preservación o propiedad se trata. Así, grupos más diversos, pero notadamente de matrices étnicas afroindígenas (resaltamos ese aspecto, pues comunica con las narrativas de mestizaje caras al modernismo brasileño) se iconizan mutuamente, y adquieren protagonismo y maestría, no por concesión o adecuación, sino como desafío de apertura de los cuadros estrechos de la nacionalidad para horizontes contemporáneos y otros futuros posibles.

Palabras clave: Patrimonio inmaterial; Performance; Jongo. 


\section{1 - A música - signo privilegiado da construção de uma memória "nacional"}

Nos anos de 1930, marcados pelas pesquisas e estudos afro-brasileiros, destacamos a composição de um acervo musical produzido a partir do projeto "Missão de Pesquisas Folclóricas", capitaneado por Mario de Andrade e Oneyda Avarenga. No ano de 1938, pesquisadores da Missão partiram de São Paulo rumo ao Norte e Nordeste do Brasil para registrar, com diferentes aparatos e suportes (anotações, fotografias, gravações, eventualmente filmes), manifestações culturais brasileiras. Percorrendo diferentes estados do país, foram recolhidos "exemplares musicais" de variados tipos, origens e estilos.

O material recolhido pelos pesquisadores era volumoso. Tratava-se de um momento em que a modernidade na qual os pesquisadores estavam inseridos "busca[va] capturar elementos de um Brasil 'tradicional', 'autêntico', que se desfaz!” (SANTOS, 2008, p.41). Como afirma Carlos Augusto Calil, no texto de apresentação da caixa de CDs com o material da Missão,

\footnotetext{
Mario [de Andrade] padecia da urgência de seu contemporâneo Adorno. O vertiginoso progresso cientifico e a avassaladora chegada da indústria cultual ameaçavam o remanescente das atitudes de resistência espontânea de humildes e marginalizados (ANDRADE, 2010, p.4).
}

Era um momento relativamente novo e impactante, de rápida difusão da indústria cultural e de entretenimento, de processos de comercialização das artes e de produção em massa de imagens e sons que circulavam como mercadoria em estratos ampliados da população das cidades em rápido crescimento e modernização. Era contra a exploração comercial dos elementos populares e a formação de um consumo urbano indiferenciado que Mario de Andrade se voltava, distinguindo o popular do "popularesco".

O popular "autêntico", diferenciado, passível de ser "recuperado" por paciente trabalho de "garimpo", estava, portanto, atrelado a uma ideia de "folclore" (Oliveira, 2008) - construções sonoras relativas a uma ambiência rural, anteriores às formas industriais de criação e de performance, e que eram expressão de modos de vida tradicionais, locais, "típicos", ou seja, vestígios de um mundo "pré-moderno". As ideias de "origem" e de "autenticidade", que embasavam os eixos dos estudos folclóricos, de um modo ou de outro também impregnaram as políticas oficiais de cultura “aplicadas” à música.

A cena musical brasileira foi também um foco privilegiado para os debates acerca da "identidade nacional" e da "autenticidade" das criações, trazendo inspiração e muitos dos elementos chave para as reflexões a respeito da construção de um "patrimônio artístico nacional". Nesse sentido, o acervo musical produzido a partir do projeto Missão de Pesquisas Folclóricas 
exemplificaria os esforços de "orquestrar" uma pluralidade como forma de produzir uma identidade (nacional). 1

Podemos entender esse período como um momento de produção de uma "memória nacional", num sentido específico. Como afirma Anna Paula de Oliveira, Mario de Andrade

(...) Atesta o desconhecimento das tradições musicais populares por parte dos compositores e do público brasileiro, por isso defende a pesquisa e o registro destas expressões para a consolidação de uma memória nacional, e para a formação de um arquivo de fontes a ser explorado na construção de uma música erudita legítima” (op.cit., p 25).

Mais adiante, a autora enfatiza que aquela proposta de memória atravessará os discursos de patrimonialização no Brasil:

\begin{abstract}
O valor histórico das obras emerge de uma iniciativa de recomposição cultural, o popular afirmado está circunscrito a condições específicas de produção, e a exaltação estética dos objetos a serem tombados obedece a critérios muito rigidamente demarcados (ibidem).
\end{abstract}

A partir da década de 1960, esses fundamentos modernistas "autenticidade", "origem" - começam a ser ressignificados, problematizados e também questionados no cenário da música popular - período de construção da MPB como gênero e do movimento tropicalista.2

É com esses referenciais que pretendemos considerar certos aspectos e efeitos das políticas patrimoniais, hoje, no contexto urbano. Por um lado, a política de patrimonialização - ao legitimar a ideia de "imaterialidade" como aproximação ao sentido de "cultura" que a antropologia formulou e difundiu, especialmente na primeira metade do século $\mathrm{XX}$, em direções predominantemente distintas daquelas dos estudos de folclore - traz novos ares ao cenário cultural, ao permitir que a própria ideia de patrimônio se transforme com base no caráter vário e variante da cultura popular; por outro lado é preciso estar atento para perceber e compreender como as categorias centrais da modernidade (que permearam a construção do discurso patrimonial no Brasil) ainda se fazem presentes nas politicas oficiais de cultura.3

No cenário musical brasileiro da atualidade, algumas manifestações, apesar de estarem em paralelo ao repertório divulgado pela mídia em geral, não se mantêm em completo isolamento. De forma muito particular, essa musicalidade segue dialogando com aquilo que transita nos diferentes tipos, estratos e "nichos" dos meios de comunicação, modificando e sendo modificada

\footnotetext{
${ }^{1}$ Para Mario de Andrade, bem como para outros intelectuais, a música popular "era fonte inspiradora da nacionalidade, desde que ancorada no passado da cultura popular oral, material rico e bruto a ser lapidado pelo mundo erudito" (NAPOLITANO,2007, p.41).Ela seria o elemento (ou emprestaria o modelo) capaz de agregar e construir uma nação. Quanto a isso, cabe também mencionar que o projeto marioandradino se tornou referência, inspiração ou precursor de outras dezenas de iniciativas de mapeamento de sonoridades (e visualidades e narratividades) no Brasil, isto é, obras de coleta e documentação e interpretação de manifestações populares não observadas pela cultura urbana de consumo.

${ }^{2}$ Defendemos a ideia de que a dualidade MPB - Tropicália não constituiu propriamente um abandono da sensibilidade modernista ou da atração pelo popular/folclórico numa busca de autenticidade, e sim uma performatização inovadora, que incluía atitudes de ruptura e crítica. Ou seja, que a musicalidade mesma do popular (em regime de reprodutibilidade, isto é, discos, tevê etc.) cultivava aproximações e misturas de universos que o modernismo ainda via como disjuntos e opostos. (DINOLA, 2014)

${ }^{3}$ Essa afirmação não tem intenção crítica; será retomada nas considerações finais.
} 
por essa ampla produção, e propiciando, afinal, novas maneiras de fazer e pensar a música e os elementos que já foram (e continuam sendo, em parte) valorizados como parte da "identidade brasileira".

As políticas de patrimonialização atuam sobre a diversidade das culturas populares no contexto urbano, aquele onde em princípio (segundo as concepções de modernização) a artesanalidade, o tempo comunitário e a tradicionalidade das formas folclóricas se perderiam. É nesse contexto que está inserido o "Grupo de jongo da Serrinha", um principais grupos de jongo que compõem o "Jongo do Sudeste" - reconhecido como patrimônio imaterial -, e que será enfocado adiante. A intenção será refletir sobre significados de um duplo desenvolvimento: as transformações dos regimes e modos do patrimônio (representada, basicamente, pela instituição da categoria do "imaterial”), em paralelo ou confluência com as modificações das cenas musicais urbanas periféricas "desfolclorizadas", a emergência de outras noções e experiências do “popular”, e seu afastamento em relação ao paradigma da identidade e da nacionalidade.

\section{Nação e nações no cenário musical - identidade(s)}

Durante a década de 1960, o projeto de Mario de Andrade - que, com certa licença metafórica, pode ser resumido como o de "construir uma nação através da música” - é revisitado pelos mentores da MPB (mas, é claro, em outro plano de atuação artística e intelectual). O ideário nacional-popular é reforçado pelo intenso debate ideológico do período, quando a expressão nacionalista (mas geralmente com algum viés cosmopolita, mesmo nos círculos que rejeitavam influências estrangeiras e o "imperialismo") se tornou um valor político e cultural a ser conquistado e preservado.

Em um ensaio intitulado "Ruídos da música popular”, Beatriz Resende (2002), ao visitar o tema da importância da música na constituição da cultura nas grandes cidades, afirma que as dicotomias litoral/sertão, cidade/interior, morro/asfalto, centro/periferia, estariam se dissolvendo a partir do início do século XXI, mas que foram significativas e operantes para pensar e retratar o Brasil na geração anterior, e mostra como isso se expressou em diferentes canções. A autora sugere que tais dicotomias são importantes para entender diferencialmente o cenário atual, marcado por conflitos e dramas bem distintos, e que inclusive questionam os que se impuseram durante a vigência daqueles limites e oposições, ainda associados ao modernismo (em sentido amplo de 'crença nas rupturas da modernização') e às visões "puristas" e "folclorizantes" em torno da música popular, ainda impregnadas de dicotomias eurocêntricas.

Lembremos novamente que a perspectiva "totalizante" teria sofrido seu primeiro abalo ainda no final dos anos 1960 com surgimento do movimento tropicalista (1967) que, além de questionar esta visão nacional-popular, já adotava uma ideia internacionalista e receptiva à cultura de massa (MELLO, 
2008). O conceito de "nacional", ainda muito atrelado à ideia de Estado-nação, começa a ser, portanto, ressignificado. Como afirma Santuza Naves, "a síntese das três raças que constituiria o Brasil, defendida pelos modernistas, teria dado lugar para uma perspectiva fragmentária que enfatiza comunidades especificas" (NAVES, 2010, p.18).

Portanto, a ideia de nação estaria, agora operando em redutos periféricos, cujas identidades se criariam a partir da articulação do local (por exemplo, a comunidade específica) com o global (por exemplo, a etnia negra e suas formas de afirmação no planeta) (idem).

Esse abalo na estética totalizante possibilitou diversas ressignificações, que passam desde o conceito de "nação" até novas musicalidades representando "vozes das comunidades" cantando "vários "Brasis" (MELLO, 2008). O importante é percebemos que os discursos questionadores dessas leituras "totalizantes" - que até bem pouco tempo exerciam grande influência e legitimidade neste processo de "invenção" da nação - são fundamentais para o surgimento de uma cena musical, tal como vista hoje, caracterizada por um regime diferente daquela diversidade mapeável pelos esquemas identitários anteriores.

Portanto, no campo musical, o ruir deste imaginário (o de um país miscigenado, sem muitos conflitos entre raças e classes sociais) se dá e é problematizado na "mudança do local partida dos enunciados" (MELLO, 2008): uma inversão do centro para as periferias - as camadas populares (os redutos do funk e do hip-hop). Trata-se de uma cena musical, agora, marcada pela proliferação dos discursos de diferentes grupos e comunidades, discursos que são, eles mesmos, musicais: pesquisas de sonoridades e narratividades com premissas distintas das “aquarelas de Brasil” (RESENDE, 2002).

Neste sentido, o campo musical - com sua especificidade de agentes, de capital simbólico, de meios de (re)produção e de formas de disputa - dentro de sua dinâmica especifica, passa a ser um locus de produção de diversidades que não cabem nas sínteses da construção nacional do período de institucionalização do modernismo.

Isso nos leva diretamente a uma das questões centrais deste artigo, relativas ao campo patrimonial, e mais especificamente ao do patrimônio imaterial. Comparando as mudanças ocorridas no campo musical e no campo patrimonial (neste caso, a partir da Recomendação da UNESCO de 1989 e a Convenção do Patrimônio Imaterial de 2003), observamos que o olhar para as diferenças e a abertura para as diversidades - a valorização de alteridades - não são ideias gestadas apenas no campo patrimonial, nem questões especificas dele.

Em ambos os campos, os olhares se voltam para os locais de partida dos enunciados. As mudanças ocorrem, portanto, em torno da sensibilidade e da elaboração do que se costumava chamar de diversidade cultural no Brasil - o objeto de mapeamento identitário transformado numa espécie de território de experimentações. 
A questão que se coloca é: o que haveria de específico no campo do patrimônio? É nele que se inicia a abertura de um processo de emersão de memórias coletivas singulares a certas instâncias da(s) narrativa(s) nacional(is) - o que, no caso brasileiro, culminou nos anos 2000, embora já viesse se fortalecendo especialmente a partir da década de 1980 - na qual se iniciou o desmonte institucional do período ditatorial e a partir de movimentos sociais e associações diversas da sociedade civil o reconhecimento dos direitos (especialmente culturais) dos grupos ditos minoritários incorporou-se (efetiva, embora incompletamente) no texto na Constituição Federal de 1988.

\section{Regimes de patrimonialização e de memoração}

No artigo "Memória e patrimônio: por uma abordagem dos regimes de patrimonialização" (2015), Jean Davallon propõe traçar um paralelo entre as ideias de memória e patrimônio através da análise de regimes de patrimonialização. Para isso, ele sugere, como ponto de partida, traçar uma oposição entre os termos memória (coletiva) e patrimônio - aquela entendida como os saberes que se mantêm mediante a existência de grupo social (que garante a sua transmissão), e este entendido como resultado de um estatuto de reconhecimento. Portanto, ao contrario da memória, na ideia de patrimônio (o autor considera o patrimônio material, categoria "clássica" desse campo) a "transmissão " não se apresentaria. O patrimônio, na medida em que constituído de objetos materiais que são índices, vestígios de um passado descontinuado em relação ao presente, não seria um saber transmitido , mas sim o centro ou fulcro de um saber "reconstruído". Se não há transmissão, o laço entre passado e presente se daria somente através de uma construção.

Nesse sentido, o patrimônio seria algo que tem dimensões para além do grupo detentor daquele saber. Afinal, a transmissão - que no caso do patrimônio é garantida pelos suportes da memória (transposição da oralidade para a escrita, uma espécie de "materialização" do imaterial) - ocorreria também entre grupos sociais e culturas distintas.4

Para o autor, se por um lado haveria essa distinção entre memória e patrimônio, haveria, por outro, uma "equivalência simétrica" entre "memoração" e patrimonialização. Estas noções são associadas pelo autor aos processos de produção de saberes (sendo o primeiro caracterizado por sua forma mais artesanal). De modo geral, a principal função do saber seria a de "reconstituir a memória perdida do objeto e de seu mundo de origem, de seu

\footnotetext{
4 É importante pontuar a diferença que o autor estabelece entre memória social e memória histórica a partir da análise que faz da proposta de Halbwachs: "Se admitimos a distinção proposta por Halbwachs entre memória e história, a memória social - chamada também de memória cultural - pertence, evidentemente, ao registro da memória, no sentido em que ela tem a capacidade de dar continuidade à transmissão no seio de um grupo. Em oposição, sabemos que a reconstrução histórica ou patrimonial é feita a partir do tempo presente e pressupõe a mediação dos documentos (o arquivo), e não a dos testemunhos ou documentos produzidos para fins de transmissão. A diferença fica evidente com a história, que, segundo afirma Halbwachs, "é necessariamente um atalho e é por isso que comprime e concentra, em alguns momentos, evoluções que se estendem ao longo de períodos inteiros: é nesse sentido que ela extrai as mudanças da duração"(Halbwachs, 1997 [1950], p. 165) - Davallon, 2015, p. 62)
} 
contexto de produção, isto é, a transmissão memorial que está ausente (DAVALLON, 2015, p.52).

Ao dirigir seu olhar para o patrimônio imaterial, Davallon afirma que se trata de um "regime de patrimonialização diferente" daquele atribuído ao patrimônio material, que em vez de ser considerado como categoria universal aparece como "um modo especifico de produzir patrimônio". Ao focalizar os processos de patrimonilaização do imaterial, o autor enfatiza o papel central da memória social como "meio de produzir saber". Tal produção de saber atuaria de forma muito significativa como legitimadora da autenticidade: "o desafio é a garantia da natureza semiótica daquilo que está diante de nós, homens do presente" (DAVALLON, 2015, p.52). Na ausência da "materialidade", o saber construído - isto é, aquele constituído por meio da escrita ou "inscrição" da memória coletiva em memória social - "irá, assim, suprir um saber lateral sobre o objeto que não foi transmitido" (ibidem).

Do ponto de vista da patrimonialização

Todo patrimônio deve sua existência a um processo de construção social. Esse processo de construção social não é isento de tensões e requer a identificação dos tipos de discurso patrimoniais e dos jogos complexos e dinâmicos pelos quais se define a legitimidade dos enunciados. (idem).

Assim, trazendo para o nosso caso especifico, do jongo da Serrinha, o olhar deverá voltar-se para os elementos que, acionados no tempo presente (período de patrimonialização do jongo), "equilibram" os discursos antagônicos sobre as diferenças existentes entre o jongo dançado na atualidade e o jongo "autêntico" dançado no passado na Serrinha (ver adiante).

\section{O Jongo da Serrinha}

Davallon, ao tratar das especificidades do processo de patrimonialização do imaterial, nos alerta para a singularidade que envolve cada processo de produção de saber. Ao enfatizar o papel da memória social nesta construção, o autor nos instiga a pensar o patrimônio como uma categoria discursivamente construída. Se essa ideia, em si mesma, não é nova, cremos que ainda há dimensões a explorar nos efeitos de ressonância e dissonância que as diferentes vozes, ligadas a este processo, produzem.

No caso do jongo da Serrinha - mas com paralelos importantes em relação a várias outras manifestações culturais que vêm ocupando o espaço do imaterial -, fica bem marcado o modo com que alguns dos elementos que caracterizam os processos de patrimonialização se fazem presentes no discurso nativo. Quanto a isso, anteciparemos brevemente um dos pontos principais deste trabalho, e a partir dele faremos um breve esboço do caso em tela.

Na pesquisa desenvolvida durante seu doutoramento, P. Simonard (2005) observa "preservar" e "preservação" como categorias nativas presentes nos discursos das figuras emblemáticas do grupo. Para o autor, são "categorias 
presentes nos discursos de mestre Darcy [personagem central, que será abordada adiante] e dos 'herdeiros' de seu trabalho" (op.cit.p.o9). À "preservação" seria atribuído o sentido de salvar, resguardar, defender. Tais características nos remetem ao sentimento de perda, ou melhor, a uma "retórica da perda", mas que, agora, se faz presente no discurso nativo.

Entendendo a tradição, nos termos de E.G.Coutinho (2002), como algo "vivo", como uma "objetivação da ação humana" que se transmite no tempo, não por uma "reprodução mecânica objetiva", mas num "processo de reconstrução" em que a cultura é afetada e redefinida pelo esforços do sujeito (idem), buscaremos, a partir de certos protagonismos, atentar para o dinamismo "interno", intrínseco à tradição 5. Veremos que a "retórica da perda" é apropriada pelo grupo (e, portanto, presente nos processos contemporâneos de patrimonialização do imaterial), não como acionamento ou legitimação dos mecanismos de fixação, "congelamento" ou "fossilização" (Coutinho, 2002) da tradição, e sim como práticas que viabilizam transformações que não se apegam às "perdas", antes as tematizam para reinventar-se.

O termo jongo, de modo geral, se refere a uma prática performativa que envolve música (palavra cantada e instrumentos musicais, especialmente os percussivos [tambores]) e dança (homens e mulheres dispostos numa roda). Sua origem é atribuída às rodas de canto e dança que se organizavam durante os festejos dos dias dos santos católicos e no decorrer das festas familiares (quando permitidas pelos senhores de escravos). Trata-se de uma prática que, no século XIX, se manifestava principalmente na região Sudeste do Brasil. Neste período, dá-se na região uma concentração de escravos - trazidos de outras regiões do país ou diretamente da África - demandada por uma economia em ascensão: crescimento das lavouras de café (região do Vale do Paraíba) e de cana-deaçúcar (norte fluminense e região sul do Espírito Santo).

No inicio do século XX, com o fim da escravidão e o declínio da economia cafeeira na região do Vale do Paraíba, parte dessa população de ex-escravos e seus descendentes iniciaram um processo de migração para a então capital do Brasil - a cidade do Rio de Janeiro.

Esta narrativa migratória se faz presente na construção da identidade do bairro de Madureira - local onde se encontra o Morro da Serrinha, ocupação que se inicia nos anos de 1920, um período de grandes transformações no bairro. Como afirma Simonard (2005), são transformações também vinculadas à vida cultural, principalmente, às festas populares. A identidade da comunidade passa a ficar menos vinculada ao local de moradia e mais baseada nos "laços de amizade e compadrio estabelecidos nas rodas de jongo e samba"

\footnotetext{
5 Mas lembrando, com Gregory Bateson (1972; especialmente partes V e VI) que toda entidade complexa que tem continuidade temporal implica sempre uma relação entre "interior e exterior".
} 
(p 13). Para o autor, o jongo empenharia um papel significativo na consolidação das estruturas de integração e controle social.

É importante também enfatizar a aproximação feita entre o samba e o jongo - considerado como o "pai" do samba. No acompanhamento/ relato da construção de identidade, Simonard se apropria da expressão "famílias do samba" (CASTRO, apud SIMONARD, 2005) para denominar as primeiras famílias que ocuparam a Serrinha. A ideia de família é central, pois marca aspectos ligados a uma descendência - e figurações de ancestralidade -, ou seja, a um laço maior que permeará o discurso de construção do grupo.

As mudanças que ocorreram na comunidade a partir dos anos 1950 novos ciclos migratórios (populações oriundas do Norte e Nordeste do Brasil), ascensão do samba entre as gerações mais jovens (Escola de Samba Império Serrano campeã por três anos consecutivos) - propiciaram um esvaziamento da função atribuída ao jongo na comunidade. As "famílias do samba" começaram a perder sua influência. É nesse período que uma família começa a desempenhar uma espécie de liderança em prol do jongo - a família Monteiro, na qual se destaca um dos grandes representantes dessa prática, o “mestre Darcy”.

$\mathrm{Na}$ prática do jongo, considerado inclusive em seus aspectos religiosos, uma das funções dos tambores seria de estabelecer uma comunicação entre os jongueiros e as entidades espirituais. Segundo relatos variados, era por receio de que as crianças se tornassem vítimas da magia atribuída ao jongo que, em principio, era vedada a participação de crianças nas rodas. Isso, ao logo do tempo, somado às mudanças ocorridas no interior da comunidade, começa a se tornar um elemento complicador para a transmissão da prática tradicional no interior no grupo - e os jongueiros mais velhos estavam morrendo.

No depoimento que mestre Darcy faz ao vídeo “Caxambu de Sá Maria”, o jongueiro afirma que já participava das rodas desde muito pequeno, com quatro anos de idade (SIMONARD, 2005). Para mestre Darcy, o fato de sua mãe (Vovó Maria Joana) ser jongueira cumba (termo utilizado para designar jongueiros que dominavam as artes da magia), o preparava para poder participar das rodas. Vemos aqui como a "tradição viva" (distinta da ideia de tradicionalismo) é algo que ativa, impulsiona, permite ou mesmo exige mudanças.

Nesse processo dinâmico, mestre Darcy aparece - e o depoimento documentado no vídeo é um entre muitos exemplos - como uma figura central na ressignificação e reconstrução da tradição. Por estar fortemente ligado à tradição é que ele pode e se permite "romper" com ela ao mesmo tempo que em "defesa" dela.

\section{1- O jongo "de apresentação"}

A década de 1960 também é bastante emblemática para o jongo. Em paralelo ao circuito musical de construção da MPB, os organizadores do jongo da Serrinha viam as rodas de jongo desaparecer dos terreiros. Foi então que membros da família Monteiro, liderados por Mestre Darcy, decidiram formar o grupo “Jongo Basam” (nome resultado da palavra samba). 
Com o objetivo de evitar a "morte do jongo" na Serrinha, bem como seu desaparecimento no cenário cultural das manifestações de origem afrobrasileira, mestre Darcy incentiva o que Simonard (2005) denominou como uma "profissionalização dos jongueiros". Seria através desse processo que o jongo da Serrinha se fortaleceria novamente, porém mais definido como grupo. Segundo o autor, Mestre Darcy inicia um esforço para desenvolver um trabalho profissional: fazer com que seus participantes pudessem viver do jongo ou complementar sua renda com a renda das apresentações. As rodas do Mestre Darcy começam a se distanciar da forma (e também da motivação) inicial dos antigos jongueiros. Há, portanto, uma quebra no modo de organização das rodas de jongo na Serrinha - elas se desligam da vinculação ao círculo e aos ciclos das atividades do grupo (aquilo que o olhar moderno associava ao "comunitário" e autêntico) e passam a ter um referente mais forte de objetivação (a apresentação). Processo que é observado e referido inclusive por grupos ligados a outras manifestações patrimonializadas (BERTOLO, 2015).

Porém, é importante frisar que todo este processo faz parte do discurso, elaborado por Mestre Darcy, de preservação e transmissão do jongo. A preservação se daria por meio da disseminação para além do território da Serrinha. Como enfatiza Simonard, o mestre jongueiro visava atrair o público "classe-média erudita" através da produção de bens culturais "alternativos" fora do catálogo comum da indústria.

Nesse "projeto", a ideia de "renovação" se torna peça chave no discurso (e na prática) do Mestre Darcy. Para ele, para se manter viva, a tradição teria que manter um diálogo com o tempo presente. Isso é o que permitiria ao jongo dialogar com as novas gerações e também com o aquele novo cenário musical que já se configurava nos anos 1960. Na preservação, transmissão e "profissionalização" do jongo promovidas em torno da atuação da família Monteiro, alguns elementos desta manifestação cultural foram preservados tal como no passado, outros sofreram modificações e adaptações 6. Entre as mudanças, destacamos a introdução de novos instrumentos, como os de corda. Para mestre Darcy, o uso de instrumentos de corda nos ritmos afro-brasileiros já era muito comum, e ele atribuía ao samba esse "pioneirismo”.

Nos anos 1990, uma nova virada ocorreria naquele cenário: o "Grupo Basam" se transforma em "Grupo Jongo da Serrinha”. Ele em parte desliga sua imagem do escopo da família Monteiro e volta a se vincular ao seu "local de origem”. Neste período, Mestre Darcy produz espetáculos com o novo grupo e começa a dar aulas para o público externo à comunidade (estudantes, pesquisadores, professores, turistas, etc.). Como lembra Simonard (2005), a tradição passaria a ser "preservada" ao ser comodificada (tornada mercadoria) e comercializada como tal.

\footnotetext{
${ }^{6}$ Várias mudanças são observadas: a introdução de um novo passo, a "tabia"; a quebra do círculo do jongo durante as apresentações - a "roda" passa a ser caracterizada por um semicírculo para que o público possa visualizar os dançarinos; o jongo , antes dançado à meia noite, passa a ser dançado no horário de apresentação do espetáculo, tal como contratado; as festas não mais ocorrem vinculadas a ao calendário inicial (nos dias santificados), outras datas são inseridas (entre elas o dia da abolição da escravidão, o aniversário da Vovó Joana, e o último domingo de cada mês); por fim, a comida, antes trazida pelos participantes e que circulava na festa, é substituída por lanches (SIMONARD, 2005).
} 
Assim, um paradoxo, em princípio, se estabeleceria: "a tradição enfraquecida é revitalizada graças a uma crescente demanda do próprio mercado, saturado pela padronização da cultura de massa" (COUTINHO, 2002, p.155). Assim, nos termos da já mencionada caracterização de Carlos Augusto Calil, apresentada inicialmente neste artigo, o viés de afinidades "frankfourtianas" da concepção marioandradina é quebrado. Mas o ponto importante, para o qual queremos chamar atenção e que é central no argumento deste trabalho, é que se trata de um paradoxo criativo, pois é nesse processo que ocorre o fortalecimento de novas identidades. Para se diferenciar daquilo que estava sendo produzido no mercado, são selecionados e valorizados os elementos característicos da comunidade, ligados - discursivamente, e em práticas construídas em processos que mobilizam aprendizados e trocas - a um passado "distante" e a uma concepção particular de africanidade (SIMONARD, 2005).7 Como afirma o autor, Mestre Darcy percebia a tradição como um "processo de recriação do passado a partir da interpretação consciente e criativa da cultura" (SIMONARD, 2005, p. 37).

Para concluir este esboço e passar às considerações finais, é possível resumi-lo afirmando que a transmissão das formas do passado é criadora. A tradição é uma atividade de seleção, valoração e interpretação (no tempo presente) do acervo cultural ligado ao passado. É na dualidade de conservação e ruptura que a dinâmica interna de um grupo se expressa, o que se dá, no caso do jongo da Serrinha, pela "ruptura" com os "dogmas" de gênero (musical) e com os "tabus" de acesso e participação, num esforço de comunicação com novas gerações. Com elementos contemporâneos recebidos tradicionalmente (os saberes musicais e de dança, as convivialidades etc.) e com vocabulários emprestados à sociedade abrangente, iconiza-se um passado que fala ao futuro porque é atual. Portanto, o que mantem o jongo vivo na Serrinha é o reconhecimento, no tempo presente, de que aquele elemento é parte do patrimônio do grupo, ou talvez: de que pode haver um grupo autêntico em torno de um patrimônio (imaterial).

\section{Algumas considerações}

Diante da dinâmica que envolve esta prática performativa, o desafio da patrimonialização do imaterial se apresenta na forma de atribuir a algo que está sempre se transformando o reconhecimento de que ainda é "o mesmo". Ao contrário do que ocorre no processo de patrimonialização do material, como afirma Davallon (2015)

\footnotetext{
${ }^{7}$ Deixamos aqui marcada a relação, a ser explorada futuramente, entre esse tipo de "iconização" e aquelas ressignificações criativas dos elementos culturais dos grupos tradicionais em suas relações com o Estado-nação e seus vários agentes, conceituada já nos anos 1980 por Manoela Carneiro da Cunha como etnicidade (a partir especialmente de F.Barth), e que dá a matriz da ideia posterior, bem mais recente, de cultura com aspas, a que faremos referência ainda, na conclusão (provisória) deste artigo.
} 


\begin{abstract}
Os saberes não servem, portanto, para reconstituir a memória perdida dos objetos a fim de atestar sua autenticidade, mas, antes, servem para validar as modalidades de existência físicas das idealidades patrimoniais, suas manifestações, e até mesmo o registro delas (...) Em cada ocasião, esses saberes são híbridos de memória e de conhecimentos construídos. Se os membros do grupo sabem o que obedece ao caráter patrimonial e o que não obedece, é por terem visto, ouvido, aprendido (op.cit., p.6o).
\end{abstract}

O desafio nesse processo seria, portanto, "traduzir sob forma de conhecimentos os saberes transmitidos implicitamente (durante as execuções) ou explicitamente (por aprendizagem)" (ibidem). A produção de conhecimento é "atravessada" por mediadores.

No entanto, cabe ressaltar que, diante da legitimidade das diferentes formas e práticas de "registro", acreditamos que é preciso considerar a atuação dos indivíduos, grupos ou comunidades como sujeitos culturais plenos, e não apenas "especialistas" nos processos de construção de memória.

Observando a patrimonialização do jongo, e levando em conta uma conjuntura na qual as politicas culturais ampliaram o acesso de diversos grupos e segmentos sociais aos recursos públicos para a produção cultural e artística (ABREU, 2015), aparecem aspectos que a nosso ver extrapolam o domínio "especialista" dos processos estatais de patrimonialização do imaterial, pois estes se tornam meios pelos quais a memória coletiva pode ser vivida e concebida como uma continuidade, na história, da visão de mundo de segmentos sociais excluídos - entendidos, estes, como testemunhas de outros mundos possíveis, isto é, formas de vida que são resistências às naturalizações historicistas do presente como simples etapa de um progresso civilizatório 8 . Nos termos sugestivamente empregados por Manuela Carneiro da Cunha, em relação aos grupos indígenas brasileiros, não se trata de fabricar uma "utopia" (narrativa) de um passado mais ou menos intocado, cujos vestígios humanos vivos deveriam ser preservados como uma espécie de documentação histórica de uma entidade nacional definida, mas de ativar novas "imaginações sociais", no diálogo com outros modos de vida e de conhecimento (CARNEIRO DA CUNHA, 2002).

Finalizamos, então, retornando ao jongo e à questão daquilo que pode estar envolvido no seu registro como patrimônio imaterial nacional (brasileiro). Cremos que a perspectiva interdisciplinar da memória social (em diálogo forte com campos como a história e a antropologia de povos e saberes de matrizes não europeias) pode perceber a patrimonialização como fenômeno comunicacional (registro, transmissão, constituição de saberes, práticas e discursos), porém num plano que inclui as dinâmicas sociohistóricas e as relações interétnicas e interculturais criadas/acionadas por agentes que participam de cosmologias diversas - e essa criatividade cultural dos processos

\footnotetext{
${ }^{8}$ Para uma crítica à domesticação e ao abuso das diferenças (na qualidade de diversidades mapeáveis sem conflitos) em discursos antropológicos contemporâneos ainda vinculados à colonialidade dos Estados-nação, cf. Velho, 2012. No referido ensaio, o autor propõe trazer para o domínio da cultura o veio da crítica nietzschiana ao historicismo. Em relação ao argumento do presente trabalho, acreditamos que a atenção às dinâmicas culturais e às ativações de "passados e presentes étnicos" apontam para uma riqueza cultural dos mundos não-europeus, que é incomensurável aos referenciais de valoração da economia hegemônica (criação de valor, nos termos de Davallon) e pode ressignificar politicamente, em termos de memória, as práticas conservacionistas e de salvaguarda fundamentadas na "retórica da perda”.
} 
transversais de memória são particularmente significativos em contextos de colonialidade, subalternidade, diáspora etc. As bases políticas e conceituais da emergência do patrimônio imaterial apontaria assim para uma diversidade (cf. ABREU, 2015) que é o terreno mesmo em que se dá aquela criatividade. Assim, políticas públicas do Estado-nação, ainda que em continuidade com mecanismos e concepções de narrativas nacionais modernas ou eurocêntricas (VELHO, 2010a), podem funcionar (e efetivamente vêm funcionando) como viabilizadores de novos conhecimentos e narrativas.

É particularmente significativo que se observem no processo do Jongo da Serrinha dinamismos socioculturais que desconstroem, muito literalmente, as noções reificadas de tradição por oposição a modernidade, e seus corolários historicistas (o progresso científico e a eficiência econômica, o "desenvolvimento nacional", o choque de civilizações [VELHO, 2010b]). Referimo-nos ao paradoxo aparente de que as políticas de patrimonialização confluam com um discurso de salvaguarda e tradicionalismo dos próprios detentores-autores-produtores dos saberes e práticas e socialidades envolvidos nessa manifestação. Deixamos aqui indicado que há afinidades mais profundas com as etnogêneses e reinvenções culturais afroindígenas que antropólogos têm apontado no Brasil, especialmente após a (e nos quadros da) Constituição de 1988. O aspecto de preservação contra a perda, que aparece no "tradicionalismo jongueiro" acionado de dentro de práticas inovadoras e de forte diálogo com grupos "modernos" e contemporâneos, ligados inclusive ao Estado-nação, pode ser entendido como uma retórica política, de modo homólogo ao que a mesma Manuela Carneiro da Cunha veio a designar, provocativamente, como "cultura com aspas" (CARNEIRO DA CUNHA, 2009). Ela mostra que aquilo que pareceria à primeira vista uma aceitação do conceito supostamente universalista de cultura, por parte de povos indígenas em suas reivindicações de direitos e identidades (no caso, em torno de direitos de propriedade intelectual) revela uma prática política de acordos pragmáticos (que não excluem disputas e críticas) com a chamada "sociedade nacional", ao mesmo tempo que mobiliza e é mobilizada por processos culturais de cuja complexidade as categorias ocidentais não dão conta.

Teríamos então, no “jongo patrimonializado”, uma instância (entre tantas outras que as políticas de patrimonialização do imaterial viabilizam) ou novo modo de criação de valor (ou de conhecimento vivo). O processo de mobilização é tão importante quanto as objetificações cujo registro ou preservação ou propriedade se trata. Assim, grupos os mais diversos, mas notadamente de matrizes étnicas afroindígenas (ressaltamos esse aspecto, pois comunica com as narrativas de miscigenação caras ao modernismo brasileiro) se iconizam mutuamente, e adquirem protagonismo e maestria, não por concessão ou adequação, e sim como desafio de abertura dos quadros estreitos da nacionalidade para horizontes contemporâneos e outros futuros possíveis. 


\section{Bibliografia}

ABREU, R. Patrimonialização das diferenças e os novos sujeitos de direito coletivo no Brasil. In: TARDY, C. (Org.) ; DODEBEI, Vera (Org.). Memória e novos patrimônios. 1. ed. Marseille: OpenEdition Press, 2015.

ANDRADE, M. Missão de Pesquisas Folclóricas - Textos. Secretaria Municipal de Cultura/ Centro Cultural São Paulo, São Paulo, 2010.

BATESON, G. Steps to an ecology of mind. New York, Ballantine Books, 1972.

BERTOLO, G. Narrativas do espólio: uma etnografia sobre o fandango e a "perda" cultural caiçara. 2015. Dissertação (Mestrado em Antropologia Social). Universidade Federal de São Carlos (orientador: Luiz Henrique Toledo).

CARNEIRO DA CUNHA, M. "Saberes". Entrevista à série Interpretes do Brasil, de Isa Grispum Ferraz. DVD Texto e Imagem/ Cinematográfica Superfilms. 26'. 2002.

."Cultura' e cultura: conhecimentos tradicionais e direitos intelectuais". In:___ Cultura com aspas. São Paulo: Cosac Naify, 2009, pp.311-373.

COUTINHO, E. G. Velhas histórias, memórias futuras. Rio de Janeiro, Ed. UERJ, 2002.

DAVALLON, J. "Memória e patrimônio: por uma abordagem dos regimes de patrimonialização" . In: TARDY, C. (Org.) ; DODEBEI, Vera (Org.). Memória e novos patrimônios. 1. ed. Marseille: OpenEdition Press, 2015.

DINOLA, S. Imagens que dão voz - Memória da canção brasileira em documentários. $1^{\text {a }}$ edição, Ed. NEA, 2014.

GEIGER, A. Uma antropologia sem métier: primitivismo e crítica cultural no modernismo brasileiro. Tese de doutorado. Programa de Pós-graduação em Antropologia Social, Museu Nacional, Universidade Federal do Rio de Janeiro, 1999.

GONÇALVES, J.R. A retórica da perda. Os discursos do patrimônio cultural no Brasil. Ed. UFRJ. Rio de Janeiro, 2002.

HALBWACHS, M. A memória coletiva. Rio de Janeiro: Vértice, 1990.

MELLO, T. "Músicos, populares e brasileiros" In GIUMBELLI, E. ; DINIZ, J.C.V. e NAVES, S. C. (org). Leituras sobre música popular: reflexões sobre sonoridades e cultura. Rio de Janeiro: 7 Letras, 2008.

NAPOLITANO, M. A Síncope das ideias: a questão da tradição na música popular brasileira. São Paulo: Ed. Fundação Perseu Abramo, 2007.

NAVES, S. Canção popular no Brasil: a canção crítica. Rio de Janeiro: Civilização Brasileira, 2010. 
OLIVEIRA, A. P. de. "Sobre os modos de administrar heranças: o samba no novo Programa Nacional de Patrimônio Imaterial” In GIUMBELLI, E. ; DINIZ, J.C.V. e NAVES, S. C. (org). Leituras sobre música popular: reflexões sobre sonoridades e cultura. Rio de Janeiro: 7 Letras, 2008.

REZENDE, B. "Ruídos da música popular " in Apontamentos de crítica cultural. Ed. Aeroplano, Rio de Janeiro, 2002.

SANTOS, N.S. "Viagens folclóricas e etnografias no Brasil: duas perspectivas de época na composição de acervos musicais”. In GIUMBELLI, E. ; DINIZ, J.C.V. e NAVES, S. C. (org). Leituras sobre música popular: reflexões sobre sonoridades e cultura. Rio de Janeiro: 7 Letras, 2008.

SIMONARD, P. A Construção da tradição no Jongo da Serrinha: uma etnografia visual do seu processo de espetacularização. Tese (Doutorado em Ciências Sociais) Universidade do Estado do Rio de Janeiro. Rio de Janeiro, 2005 .

TARDY, C. ; DODEBEI, V. "Introdução" In: TARDY, C. (Org.); DODEBEI, Vera (Org.). Memória e novos patrimônios. 1.ed. Marseille: OpenEdition Press, 2015.

VELHO, O. "Os novos sentidos da interdisciplinaridade". Mana, Abr 2010 [a], vol.16, no.1, p.213-226.

"Ciência, modernidade e identidade: diálogos entre saberes". Conferência de abertura da I Semana de Humanidades da Universidade do Estado do Rio Grande do Norte, novembro 2010 [b], 11pags, mn.

. "Usos e Abusos da Diferença”. In: Arnaldo Érico Huff Júnior e Elisa Rodrigues (orgs.). Experiências e interpretações do sagrado: interfaces entre saberes acadêmicos e religiosos. São Paulo: Paulinas Editora, Coleção Estudos da ABHR, 2012; pp. 27-44.

\section{Recebido em 11/06/2017. Aprovado em 22/07/2017.}

